\title{
Impregnation of $\mathrm{ZnO}$ onto a Vegetal Activated Carbon from Algerian Olive Waste: A Sustainable Photocatalyst for Degradation of Ethyl Violet Dye
}

\author{
Ala Abdessemed $\left(\mathbb{D},{ }^{1,2}\right.$ Shivatharsiny Rasalingam $\left(\mathbb{D},{ }^{3}\right.$ Sanna Abdessemed, \\ Kamel El Zin Djebbar, ${ }^{2}$ and Ranjit Koodali ${ }^{4}$ \\ ${ }^{1}$ Biotechnology Research Centre, BPE 73, Ali Mendjeli, Nouvelle Ville, 25000 Constantine, Algeria \\ ${ }^{2}$ Laboratory of Science and Technology of the Environment, University Mentouri Constantine, Chaabat Errassas, Constantine, \\ 25000, Algeria \\ ${ }^{3}$ Department of Chemistry, University of Jaffna, 40000, Sri Lanka \\ ${ }^{4}$ Department of Chemistry, University of South Dakota, Vermillion, SD 50679, USA
}

Correspondence should be addressed to Shivatharsiny Rasalingam; srtharsha12@gmail.com

Received 25 July 2018; Revised 3 November 2018; Accepted 21 November 2018; Published 25 February 2019

Academic Editor: Xuxu Wang

Copyright (c) 2019 Ala Abdessemed et al. This is an open access article distributed under the Creative Commons Attribution License, which permits unrestricted use, distribution, and reproduction in any medium, provided the original work is properly cited.

\begin{abstract}
This study is aimed at developing a simple and low-cost method to fabricate $\mathrm{ZnO}$-loaded porous activated carbon (AC-ZnO) prepared from the Algerian olive-waste cakes and utilize it as a photocatalyst for the degradation of Ethyl Violet dye. The synthesized AC-ZnO material was characterized using powder X-ray diffraction, BET surface area measurements, Raman microscopy, thermogravimetric analysis, UV-visible diffuse reflectance spectroscopy, and zeta potential measurements. The degradation efficiency was evaluated with Ethyl Violet (EV) dye in aqueous solution under UV irradiation supplied by a Xenon arc lamp through a Pyrex glass filter (cutoff $280 \mathrm{~nm}$ ), and the degraded products were identified by using electrospray ionization mass spectroscopy. Additional experiments were carried out under $\mathrm{N}_{2}$ flow and with isopropyl alcohol to examine the role of superoxide and hydroxyl radicals, respectively. The amount of ${ }^{\bullet} \mathrm{OH}$ radical formed on irradiated AC-ZnO was tested with terephthalic acid which can act as a chemical trap for the ${ }^{\bullet} \mathrm{OH}$ radicals. The results from this study indicate that the $\mathrm{AC}-\mathrm{ZnO}$ is a potential catalyst for the pollutant removal and the ${ }^{\bullet} \mathrm{OH}$ radicals are the key species for the degradation of EV. Further, this study opens up an opportunity to produce cheaper activated carbon support from olive wastes for environmental remediation applications.
\end{abstract}

\section{Introduction}

Semiconductor photocatalysis has become very attractive due to its potential contributions in the field of environmental remediation. In particular, $\mathrm{TiO}_{2}$ has been widely utilized as a photocatalyst for the removal of aqueous pollutants. Although most of the photocatalytic studies use $\mathrm{TiO}_{2}$ as an effective photocatalyst, $\mathrm{ZnO}$ has also gained attention due to its favorable photocatalytic properties [1-4]. The design and development of highly efficient photocatalytic materials seem to be challenging. Several methods have been utilized to prepare photocatalysts, such as sol-gel, hydrothermal process, precipitation, and impregnation [5-9]. Fabricating materials with favorable physicochemical characteristic features are key for the design of effective photocatalysts. In this regard, porous materials, which have favorable textural properties, such as high surface areas and large pore volumes and pore sizes, have been used as support to disperse semiconductor photocatalysts. Among them, activated carbon has been found to be a promising candidate because of its favorable textural properties $[10,11]$. However, commercially available activated carbons are still expensive in many countries, (especially developing ones) due to the need of processing the raw material (charcoal, coal, or carbon) by physical and/or chemical 


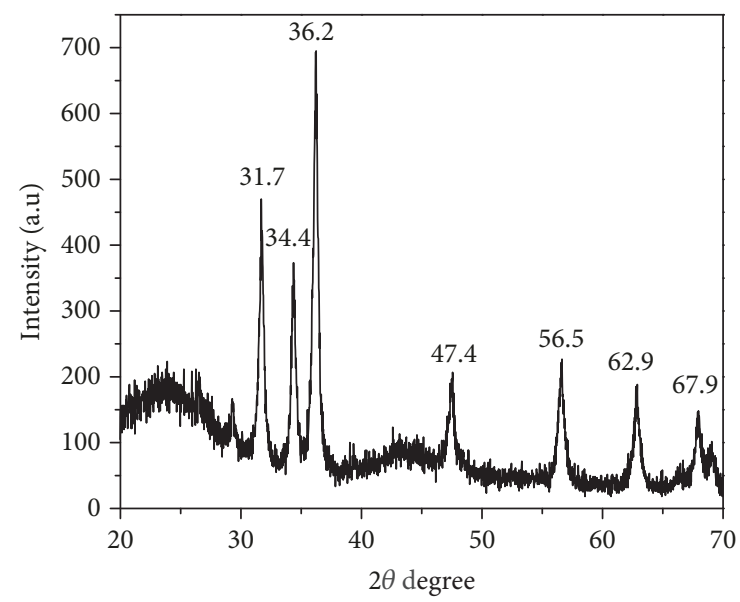

Figure 1: Powder X-ray diffraction patterns of AC-ZnO.

methods. Thus, the high costs hamper their application in several fields [12]. This subsequently leads to a growing interest in the research on the economical production of activated carbons. In recent years, a number of studies have shown that some industrial and agricultural by-products that include waste paper [13], waste tires [14], rice hull [15], corncob [16], apricot stone [17], date stone [18], and coconut husk [19] have the potential for being used as precursors to prepare activated carbons for the removal of dyes from wastewater. In this regard, olive wastes are potential candidates for the preparation of activated carbon, in comparison to the above materials. In particular, the use of lignocellulosic olive-waste cakes has received less consideration for activated carbon production $[20,21]$.

Algeria is one of the major producers of olive oil in the world [22]. During the manufacturing process of the olive oil, about $20 \%$ of oil is obtained; of the remaining percentages, $30 \%$ are waste solids and $50 \%$ is wastewater [23]. Olive-waste cakes or olive pomace, corresponding to the residue from the oil extraction process, represents a yearly average of $2 \times 10^{5}$ tons [24]. The use of this material as a precursor for the preparation of activated carbon not only contributes towards the preparation of a catalyst or adsorbent for aquatic pollutant removal but also results in the effective removal and recycling of solid wastes to valueadded products from olive oil production. Although there are several studies that have reported the preparation of activated carbon-supported materials for photocatalytic applications, existing studies are lacking in one or more of the following: (i) a low-cost preparation of activated carbon using Algerian olive-waste cakes, (ii) impregnation of photoactive $\mathrm{ZnO}$ on activated carbon, (iii) comprehensive physicochemical characterization of the support and the photoactive material, (iv) utilization of these materials for the removal of aquatic pollutants, especially, dye removal, (v) a thorough analysis of the photocatalytic by-products using electrospray ionization mass spectrometry (ESI-MS) analysis, and (vi) a systematic analysis providing a structure-activity relationship.

The present works explore the use of Algerian olive-waste cakes as potential feedstock for the preparation of activated

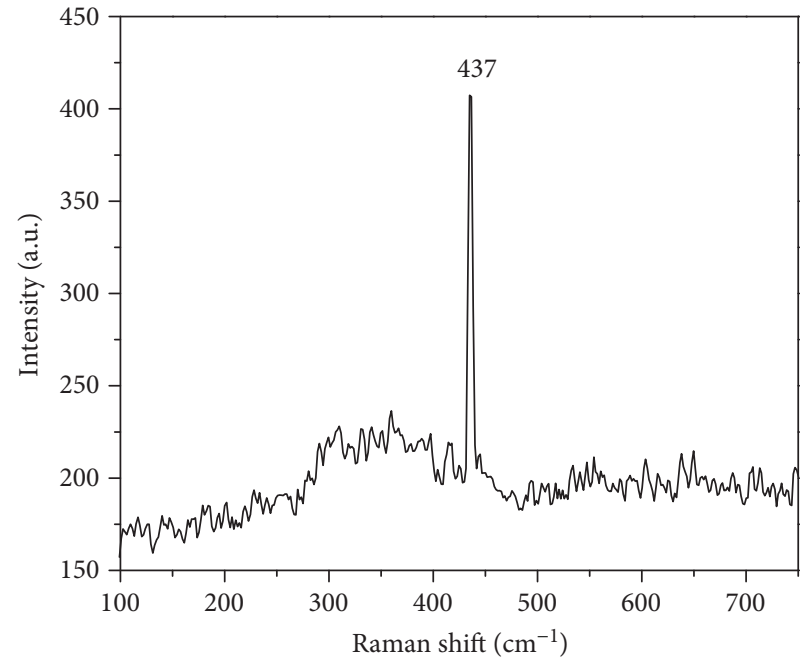

FIgURe 2: Raman spectra of the AC- $\mathrm{ZnO}$ material.

carbon (AC) as a support for impregnation of $\mathrm{ZnO}$. Further, the degradation of a cationic dye, Ethyl Violet (EV), using this sustainable catalyst prepared by dispersing $\mathrm{ZnO}$ on the $\mathrm{AC}$ catalyst (AC-ZnO) under (UV) light irradiation is also elaborated herein. Ethyl Violet (EV) is a synthetic cationic dye that belongs to the triphenylmethane (TPM) group which is highly soluble in water [25]. Among the various classes of synthetic dyes used in textile, paper, leather, cosmetic, and food industries, TPM dyes are the largest and most versatile group of dyes that plays a major role [26, 27]. These dyes are recalcitrant molecules as they are resistant to degradation. These dyes have complex aromatic structures, characterized by a chromophoric center comprising of three phenyl groups surrounding a central carbon atom [28, 29]. In particular, these TPM dyes are toxic, carcinogenic or mutagenic, and hazardous to health. Further, it has been reported that TPM can induce tumor growth in some species of fish and induce hepatic tumor formation in rodents. In addition, it causes reproductive abnormalities in rabbits and fish [30].

The study revealed that the newly synthesized material can be used for aquatic pollutant removal. Above all, the method used here for the preparation of AC is cost-effective, and thus, this study will create a path to utilize the Algerian olive waste in a creative and economic manner.

\section{Materials and Methods}

2.1. Materials. Without further purification, Ethyl Violet (EV) (Basic Violet 4) (Sigma-Aldrich) was employed as a model organic dye and deionized water (resistivity $>18 \Omega \cdot \mathrm{cm}$ ) was used to prepare the solution mixtures. Hexane (SigmaAldrich), sodium hydroxide (Acros), potassium nitrate (Acros), conc. nitric acid $\left(\mathrm{HNO}_{3}\right)$ (ACS grade), terephthalic acid (TPA) (Acros, 98\%), zinc nitrate hexahydrate ( $\mathrm{Zn}$ $\left.\left(\mathrm{NO}_{3}\right)_{2} \cdot 6 \mathrm{H}_{2} \mathrm{O}\right)$ (Sigma-Aldrich), and isopropyl alcohol (Fisher Scientific) were used as received. Optima grade water was used for the ESI-MS studies. 


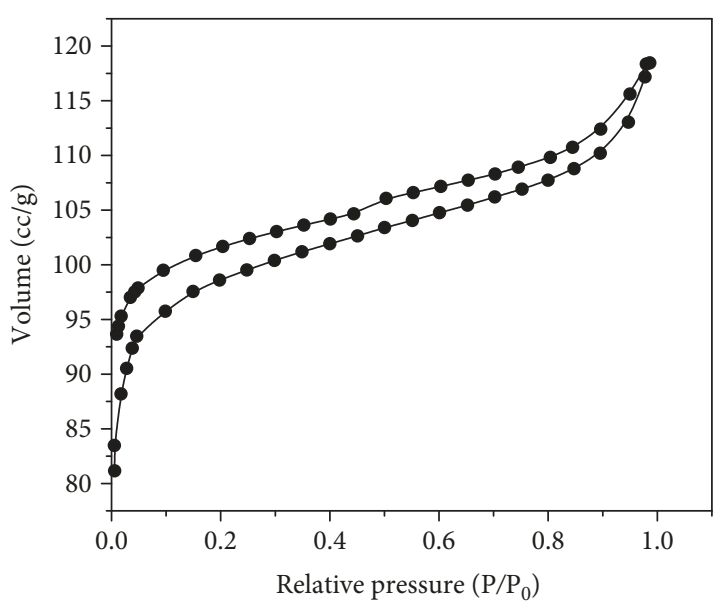

(a)

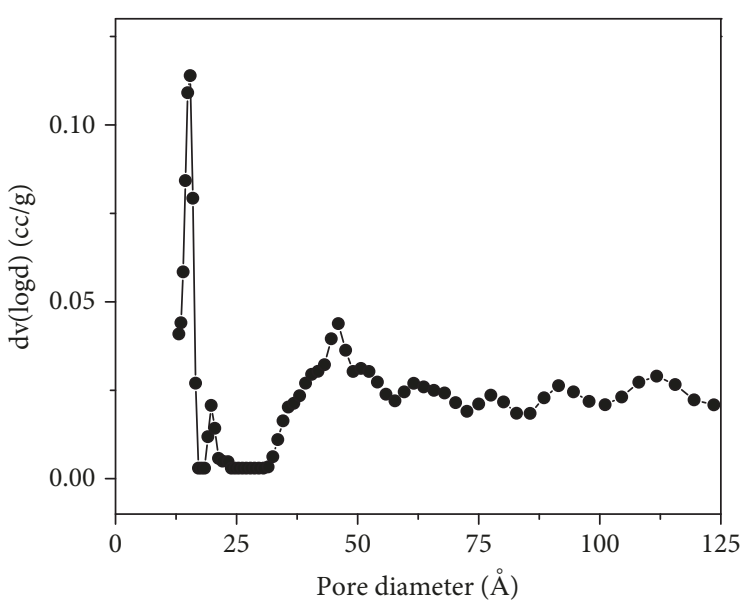

(b)

FIgURE 3: (a) $\mathrm{N}_{2}$ physisorption isotherm and (b) BJH pore size distribution plot of the AC-ZnO material.

2.2. Synthesis of the AC-ZnO Material. The olive-waste cake obtained from an oil factory located in Béjaia, Algeria, was used as raw material for the production of activated carbon support. First, the olive wastes were washed several times with tap water and then with distilled water to remove impurities; finally, it was purified by hexane to remove residual oil. The solid obtained was dried in open air. The dried olivewaste cakes were then calcined at $400^{\circ} \mathrm{C}$ for $30 \mathrm{~min}$. in a muffle furnace, and the obtained charcoal was ground and sieved using standard sieves, where the diameter of the particles chosen was between 400 and $250 \mu \mathrm{m}$. The particles were then subjected to pyrolysis on a stream of nitrogen $\left(\mathrm{N}_{2}\right)$ $\left(50 \mathrm{~cm}^{3} / \mathrm{min}\right.$.) at $800^{\circ} \mathrm{C}$ in a tubular furnace for $1 \mathrm{~h}$.

Generally, preparation of activated carbon can be classified under two types, namely, physical activation and chemical activation [31]. In particular, chemical activation uses activation agents that include $\mathrm{KOH}, \mathrm{ZnCl}_{2}, \mathrm{H}_{3} \mathrm{PO}_{4}$, and $\mathrm{H}_{2} \mathrm{SO}_{4}$. Activation with $\mathrm{KOH}$ produces activated carbon with desirable pore size distribution $[32,33]$. In addition, activation with $\mathrm{KOH}$ provides high specific surface area $\left(\sim 3000 \mathrm{~m}^{2} / \mathrm{g}\right)$ materials [34]. Although, there are no general mechanism for chemical activation, the type and amount of activating agent, the process, and the reaction condition that plays an important role in determining the structural properties of the materials. Therefore, according to a literature review, we adopted the most common chemical activation method, activation with $\mathrm{KOH}$, which provides enhanced textural properties to the material, in particular, mesoporosity [35]. In addition, activation with $\mathrm{KOH}$ has a long-term history, where the activation of coal, coke, and charcoal has been performed with $\mathrm{KOH}$ since 1970s [31, 36, 37]. It was also reported that the activation with $\mathrm{KOH}$ will also increase the adsorbing capacity of the activated carbons [38, 39].

The carbonized olive cakes were then impregnated in a solution of $\mathrm{KOH}(3 \mathrm{~N})$ with a mass ratio of $4: 1$ (i.e., $4 \mathrm{~g}$ of $\mathrm{KOH}$ per $1 \mathrm{~g}$ of pretreated carbon). After $24 \mathrm{~h}$ of stirring, the impregnated solid was separated by simple filtration of the solution and the product obtained was dried at $175^{\circ} \mathrm{C}$ and allowed to cool. After cooling, the activated carbon produced was washed several times with hot distilled water to remove the residual $\mathrm{KOH}$ until the $\mathrm{pH}$ of the depleted solution stabilized to a neutral value $(\mathrm{pH} \approx 7)$. The next step was physical activation, where the activated carbon was heated to $900^{\circ} \mathrm{C}$ for $3 \mathrm{~h}$ in a tubular furnace under a nitrogen stream $\left(\mathrm{N}_{2}\right)\left(50 \mathrm{~cm}^{3} / \mathrm{min}\right.$.). The preparation of the catalyst (AC- $\mathrm{ZnO})$ was done by impregnating the activated carbon with $\mathrm{Zn}\left(\mathrm{NO}_{3}\right)_{2} \cdot 6 \mathrm{H}_{2} \mathrm{O}(10 \% \mathrm{w} / \mathrm{w})$ followed by heating in a tubular furnace at $400^{\circ} \mathrm{C}$ for $6 \mathrm{~h}$ under a stream of nitrogen $\left(50 \mathrm{~cm}^{3} / \mathrm{min}\right.$.). $10 \%$ loading was selected as optimum loading from the preliminary adsorption studies, and a better removal efficiency was attained with the $10 \%$ loading of $\mathrm{ZnO}$. Therefore, in this study, we utilized the $10 \%(w / w)$ loading of $\mathrm{ZnO}$ on $\mathrm{AC}$ as the photocatalyst. Scheme $\mathrm{S} 1$ in the supplementary section summarizes the different steps for the preparation of the activated carbon and $\mathrm{AC}-\mathrm{ZnO}$.

2.3. Characterization. Powder X-ray diffraction (XRD) patterns were recorded at ambient conditions using the Rigaku Ultima IV instrument with $\mathrm{Cu} K \alpha$ radiation $(\lambda=1.5408 \AA)$, operated at an accelerating voltage of $40 \mathrm{kV}$, and an emission current of $44 \mathrm{~mA}$. The angle ( $2 \theta$ values) scanned range was between 20 and $80^{\circ}$ with a step size of $0.02^{\circ}$, and the scan speed was $1^{\circ} / \mathrm{min}$. The crystallite sizes were determined by applying the Debye-Scherrer equation to the peaks at $2 \theta=$ $31.7^{\circ}, 34.4^{\circ}, 36.2^{\circ}, 47.4^{\circ}$, and $56.5^{\circ}$. The diffraction patterns were analyzed using PDXL software provided by Rigaku. Raman spectra were recorded using a HORIBA Jobin Yvon LabRAM ARAMIS spectrophotometer with an internal $\mathrm{He}-\mathrm{Ne}(532 \mathrm{~nm})$ excitation laser. The unfiltered beam of scattered laser radiation was focused on the sample using a microscope objective $(\times 50)$ for an acquisition time of $10 \mathrm{~s}$. The radiation was then dispersed by an 1800 line/mm grating onto the CCD detector. Physisorption properties of the catalyst material were investigated by using the Quantachrome Nova 2200e surface area and pore size analyzer. The material was dried overnight at $70^{\circ} \mathrm{C}$ followed by extensive degassing at $200^{\circ} \mathrm{C}$, and the $\mathrm{N}_{2}$ adsorption-desorption isotherms were obtained at $77 \mathrm{~K}$. Surface areas were calculated using the Brunauer-Emmett-Teller (BET) equation within the relative pressure $\left(P / P_{0}\right)$ range of $0.05-0.30$. The pore volume was 


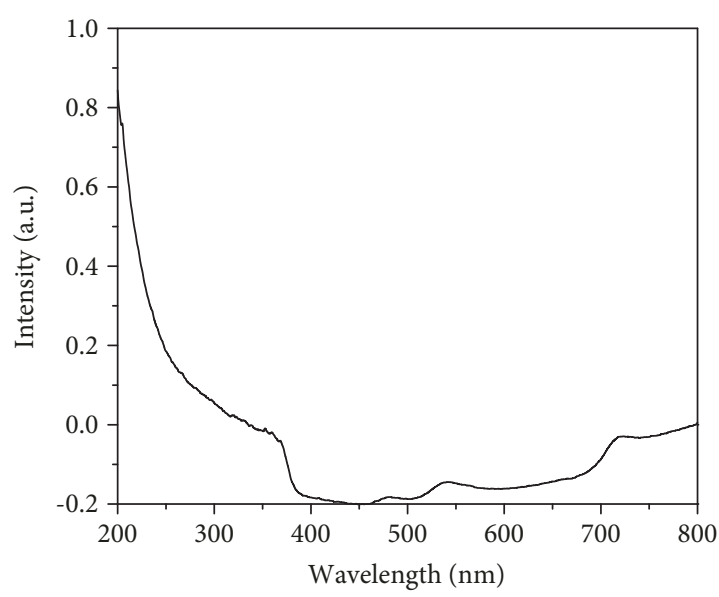

(a)

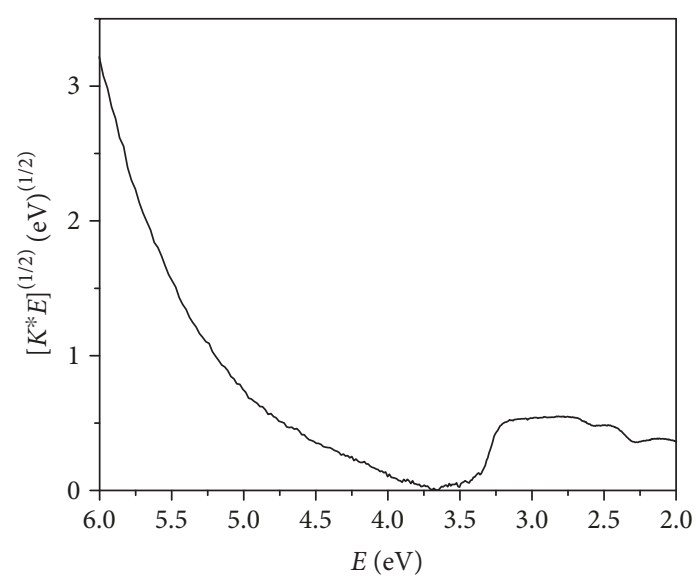

(b)

FIgURE 4: (a) DRS absorption plot and (b) Tauc plot of the AC-ZnO material.

obtained from the nitrogen amount adsorbed at the highest relative pressure $\left(P / P_{0}\right) \approx 0.99$. The pore size distribution was determined by applying the Barrett-Joyner-Halenda $(\mathrm{BJH})$ equation to the desorption isotherm. Fourier transform infrared spectroscopy (FT-IR) was used to provide information regarding the surface properties. The spectra were recorded between 4000 and $350 \mathrm{~cm}^{-1}$ on a BrukerALPHA instrument with 24 scans at a resolution of $4 \mathrm{~cm}^{-1}$ by placing a small amount of the sample on the diamond crystal. The diffuse reflectance spectra (DRS) were obtained in the wavelength range between 190 and $700 \mathrm{~nm}$ using a Carry 100 Bio UV-Vis spectrophotometer equipped with a Harrick DR praying mantis accessory. SEM images were captured on an Oxford instrument. The surface charge of the synthesized materials was recorded by autotitration using a Zetasizer analyzer (Malvern Nano ZS-90) by adjusting the $\mathrm{pH}$ of $\mathrm{AC}-\mathrm{ZnO}$-electrolyte $\left(\mathrm{KNO}_{3}\right.$ in $\mathrm{DI}$ water) suspension. Deionized water was used as the diluent. Test samples were prepared with the molarity of $1 \mathrm{mg} / \mathrm{mL}$ by dispersing known amounts of the sample in aqueous $0.01 \mathrm{M} \mathrm{KNO}_{3}$ solution. The $\mathrm{pH}$ was controlled by the autoaddition of $0.1 \mathrm{M} \mathrm{KOH}$ and/or $\mathrm{HNO}_{3}$.

2.4. Photocatalysis Experiments. The photocatalysis experiments were performed by the following procedure. $25 \mathrm{mg}$ of the photocatalyst AC- $\mathrm{ZnO}$ was dispersed in $50 \mathrm{~mL}$ of Ethyl Violet $((\mathrm{EV})$ with the initial concentration of $20 \mathrm{ppm}$ and the initial $\mathrm{pH}$ was recorded as 8-9) solution in a quartz cylindrical jacket reactor. It was noted that the $\mathrm{pH}$ influences the behavior of Ethyl Violet spectrum; there was a change in the colour when the medium of the dye solution was acidic $(\mathrm{pH}<4.5)$. In particular, the colour of the dye turned to yellow at the $\mathrm{pH}$ of 1 and green and blue when the $\mathrm{pH}$ was at 1.5 and 3 , respectively. Further, there was a widening in the band observed with a red shift when the medium was acidic. The characteristic peak for the dye solution was found at $\lambda_{\max }$ of $596 \mathrm{~nm}$, and it was found that the dye is stable when the $\mathrm{pH}$ was maintained as basic ( $\mathrm{pH}$ of $\sim 8-9$ ). Therefore, the $\mathrm{pH}$ was maintained as 8-9 throughout the experiment.
Then the suspension was stirred in the dark at $300 \mathrm{rpm}$ for $30 \mathrm{~min}$. to establish the adsorption-desorption equilibrium. Subsequently, UV light was supplied by a Xenon arc lamp (Newport $1000 \mathrm{~W}$ ) through a Pyrex glass filter (cutoff $280 \mathrm{~nm}$ ), while the reaction temperature was maintained at $25 \pm 2^{\circ} \mathrm{C}$ by channeling water in between the walls of the reactor throughout the course of the experiment $(120 \mathrm{~min}$.). The intensity of the irradiation was estimated to be $\sim 95 \mathrm{~mW} \cdot \mathrm{cm}^{-2} .5 \mathrm{~mL}$ of the reaction mixture was withdrawn initially at $10 \mathrm{~min}$. intervals followed by $30 \mathrm{~min}$. and $1 \mathrm{~h}$ intervals (i.e., 10, 20, 30, 60, and $120 \mathrm{~min}$.). Then the collected samples were centrifuged at $3200 \mathrm{rpm}$ for $15 \mathrm{~min}$., filtered through $0.45 \mu \mathrm{m}$ Millipore filter membrane, and the filtrate was then analyzed using UV-Vis spectroscopy.

Additional experiments were carried out under $\mathrm{N}_{2}$ flow (absence of oxygen) and with isopropyl alcohol (IPA) to examine the roles of $\mathrm{O}_{2}{ }^{\bullet-}$ and ${ }^{\bullet} \mathrm{OH}$ radicals, respectively. In order to detect the amount of ${ }^{\bullet} \mathrm{OH}$ radicals formed on the surface of the irradiated catalyst (AC- $\mathrm{ZnO}$ ), terephthalic acid (TPA) was used as a chemical trap. It is well known that - OH radicals rapidly react with TPA to produce highly fluorescent 2-hydroxyterephthalic acid (2-HTPA). In a typical procedure, $25 \mathrm{mg}$ of the photocatalyst was added to $50 \mathrm{~mL}$ of $5 \times 10^{-4} \mathrm{M}$ TPA solution prepared using $2 \times 10^{-3} \mathrm{M} \mathrm{NaOH}$. Then the suspension was irradiated with UV light. $3 \mathrm{~mL}$ aliquots was drawn every $20 \mathrm{~min}$. For a duration of $120 \mathrm{~min}$., filtered through a $0.45 \mu \mathrm{m}$ Millipore filter membrane, the clear solution was analyzed using Flouromax-4 (JY Horiba) fluorimeter. The fluorescence emission intensity of the 2-hydroxyterephthalic acid was recorded at $425 \mathrm{~nm}$, after excitation at $315 \mathrm{~nm}$. The intensity of the peak at $425 \mathrm{~nm}$ is proportional to the amount of ${ }^{\bullet} \mathrm{OH}$ formed.

2.5. Analytical Techniques. The remnant concentration of the dye solution after the photocatalytic reaction was estimated by UV-Vis spectrophotometric method. The absorbance was recorded by following the peak at a wavelength of $596 \mathrm{~nm}$, which corresponds to the absorption maximum of Ethyl Violet (EV). Quantification of the dye concentration 
at different time intervals was completed by using a calibration plot of EV drawn in the concentration range between 5 and $20 \mathrm{ppm}$.

A Varian 500-MS Ion Trap Mass Spectrometer was used for the identification of the dye fragments formed during the photocatalytic degradation. Ionization was completed by an electrospray ionization (ESI) source in a positive mode to separate the fragments on the basis of their mass to charge ratio. A 1:1 volume ratio of optima grade methanol and dye solution mixture was used to inject into the mass spectrometer. The operating parameters used for MS study are summarized in the supplementary section (Table S1). Finally, the remnant carbon content of the dye solution after degradation was evaluated by using a Shimadzu TOC-VCSH Total Organic Carbon (TOC) analyzer.

\section{Results and Discussion}

3.1. Powder XRD. Powder XRD patterns of the AC-ZnO prepared are shown in Figure 1. Well-defined peaks at the two theta degrees of $31.7^{\circ}, 34.4^{\circ}, 36.2^{\circ}, 47.4^{\circ}, 56.5^{\circ}, 62.9^{\circ}$, and $67.9^{\circ}$ corresponding to the diffraction planes of (100), (002), (101), (102), (110), (103), and (112), respectively, confirm the Wurtzite hexagonal structure of $\mathrm{ZnO}$ particles (JCPDS file 36-1451) [40-42].

Broad peaks at around $23^{\circ}$ and $43^{\circ}$ indicate the presence of the carbon support due to the (002) and (101) planes, respectively. These two peaks resemble with the XRD peaks obtained for the pure activated carbon support as illustrated in Figure S1 in the supplementary section. The crystallite size and the lattice constants of $\mathrm{ZnO}$ are calculated to be $209 \AA$ and $a=3.2513 \AA$, and $c=5.215 \AA$, respectively, consistent with previous reports $[43,44]$.

3.2. Raman Spectra. The Raman study further confirms the presence of $\mathrm{ZnO}$ on the carbon support. The Raman spectra of AC- $\mathrm{ZnO}$ (Figure 2) exhibit a sharp peak at $437 \mathrm{~cm}^{-1}$ corresponding to the $\mathrm{ZnO}$ structure attributed to the highfrequency E2 vibration mode of the Wurtzite phase [45, 46].

3.3. $\mathrm{N}_{2}$ Sorption Analysis. The nitrogen isotherm of the AC-ZnO material prepared is depicted in Figure 3(a). According to the IUPAC classification, the isotherm possesses a combination of type I and type II, indicating the presence of both micropores and mesopores in the material [47]. Figure $3(\mathrm{~b})$ illustrates the pore size distribution of the AC-ZnO material. The catalyst exhibits hierarchical set pores with one set of pores predominantly centered near the $13 \AA$ region and a broad set of pores in the 50 to $125 \AA$ region. The total pore volume was calculated to be $0.12 \mathrm{~cm}^{3} / \mathrm{g}$. The specific surface area of the material was found to $392 \mathrm{~m}^{2} / \mathrm{g}$. It is interesting to note that the pore volume obtained was found to be lower than that of pure activated carbon (AC) $0.22 \mathrm{~cm}^{3} / \mathrm{g}$. This may be due to the formation of the $\mathrm{ZnO}$ nanoparticles encapsulated within the pores.

3.4. UV-Visible Diffuse Reflectance Spectroscopy (DRS). The band gap of the AC- $\mathrm{ZnO}$ was determined from the Tauc plot (Figure 4(a)), which is a transformation of the absorption spectra through the Kubelka-Munk function vs. the energy

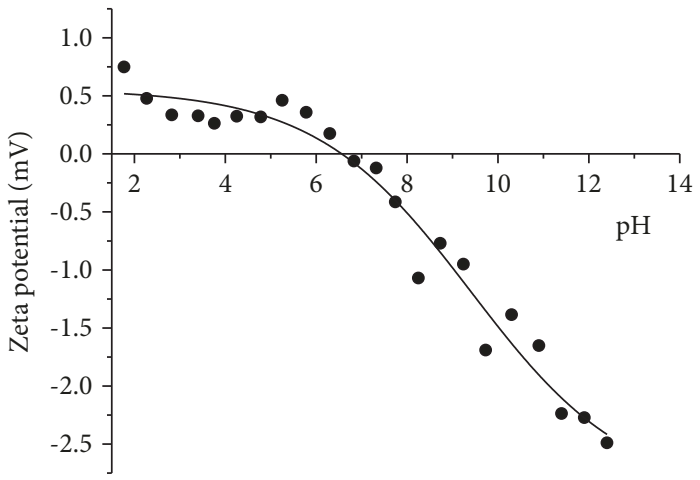

Figure 5: Zeta potential as a function of $\mathrm{pH}$ for the AC- $\mathrm{ZnO}$ material.

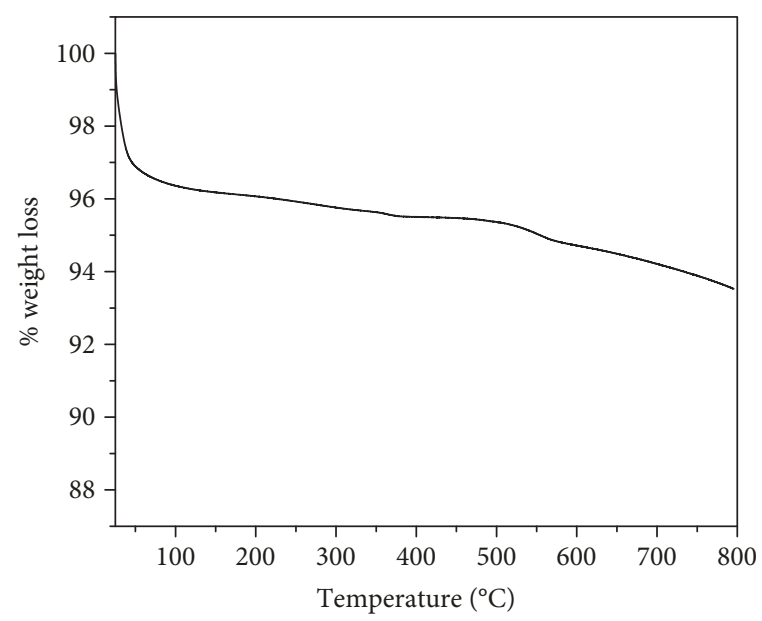

Figure 6: TGA analysis of the AC-ZnO material.

plot (Figure 4(b)). The catalyst synthesized exhibits a significant absorption below $400 \mathrm{~nm}$, which is attributed to electron transitions from the valence band to the conduction band of $\mathrm{ZnO}$ [48]. The band gap energy was calculated to be $3.75 \mathrm{eV}$ by extrapolating the steep portion of the plot in Figure 4(b) to the $x$-axis. The measured optical band gap value is close to the band gap of intrinsic $\mathrm{ZnO}$ powder and is in good agreement with the literature reports [49-52].

3.5. Zeta Potential Measurements. The change in zeta potential $(\zeta)$ as a function of $\mathrm{pH}$ is illustrated in Figure 5 . The isoelectric point (IEP) of AC- $\mathrm{ZnO}$ was found to be at a $\mathrm{pH}$ of around 6.8. These results suggest that the surface of the AC- $\mathrm{ZnO}$ material is negatively charged at $\mathrm{pH}$ values of above 6.8 , whereas the surface possesses a positive charge below the $\mathrm{pH}$ of 6.8 .

3.6. Thermogravimetric Analysis (TGA). Thermal stability of the synthesized catalyst, $\mathrm{AC}-\mathrm{ZnO}$, was studied by using TGA analysis. The catalyst was found to be stable, and around $2 \%$ of weight loss was recorded up to the temperature of $450^{\circ} \mathrm{C}$ (Figure 6), and it can be clearly seen that the impregnation decreases the carbon content and thus causes the decrease in the weight loss.

In addition, the total weight loss of this $\mathrm{ZnO}$-loaded catalyst was found to be less than that of pure activated 

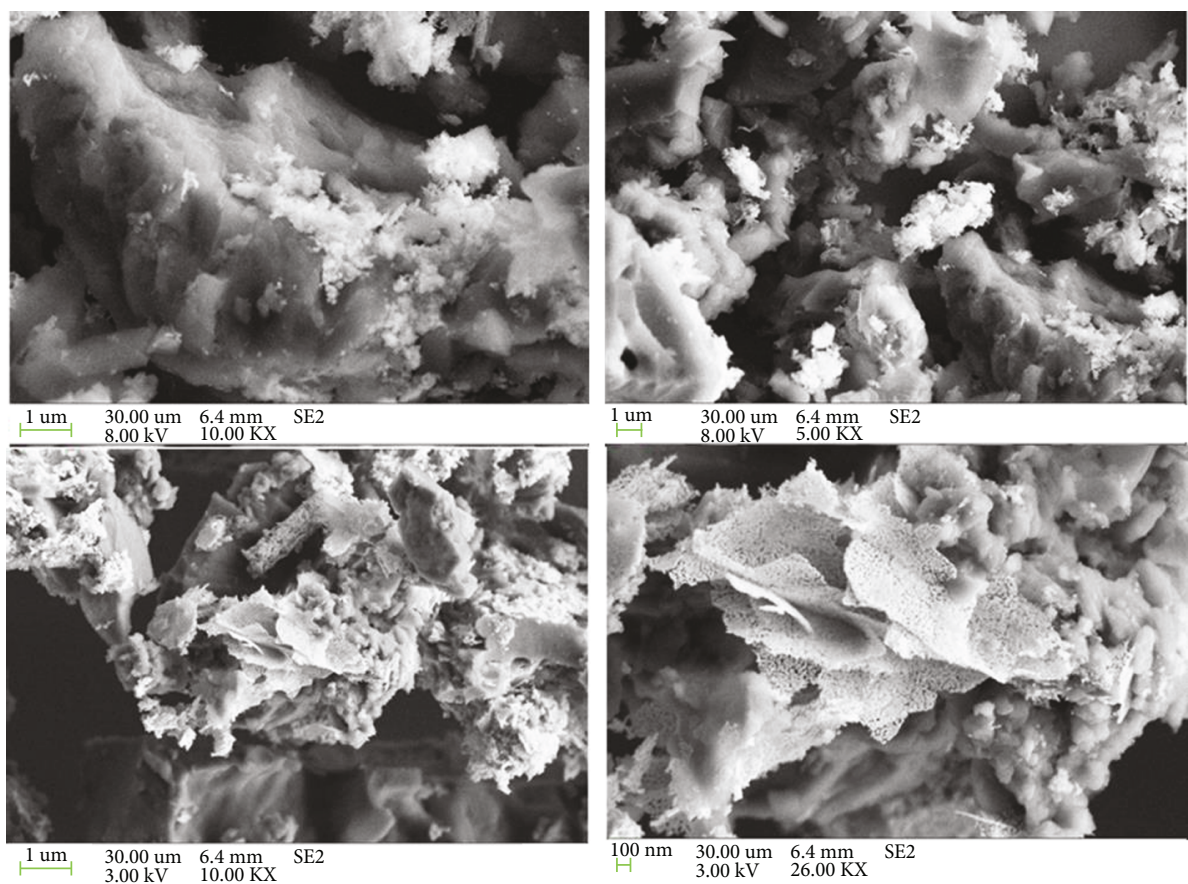

FIGURE 7: SEM image of the AC-ZnO material.

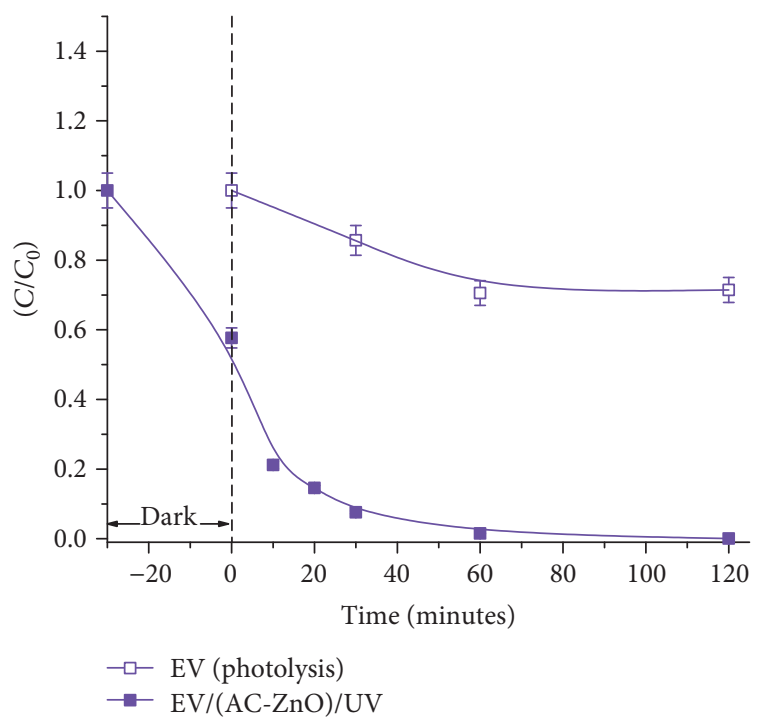

Figure 8: Plot of $C / C_{0}$ vs. time for direct photolysis $(\square)$ and the degradation of $\mathrm{EV}(\boldsymbol{\square})$ in the presence of $\mathrm{AC}-\mathrm{ZnO}$ under $\mathrm{UV}$ illumination.

carbon (AC) as illustrated in Figure S2 (3.2\%). This low weight loss further indicates the stability of the catalyst against temperature.

3.7. Scanning Electron Microscopic Analysis (SEM). SEM studies confirm the loading of $\mathrm{ZnO}$ on the activated carbon support, and Figure 7 illustrates the SEM image of the ZnO-loaded materials. It can be seen that the activated sample is in an irregular pattern with fine pores. In addition, $\mathrm{ZnO}$ particulates are deposited on the surface and in the pores of

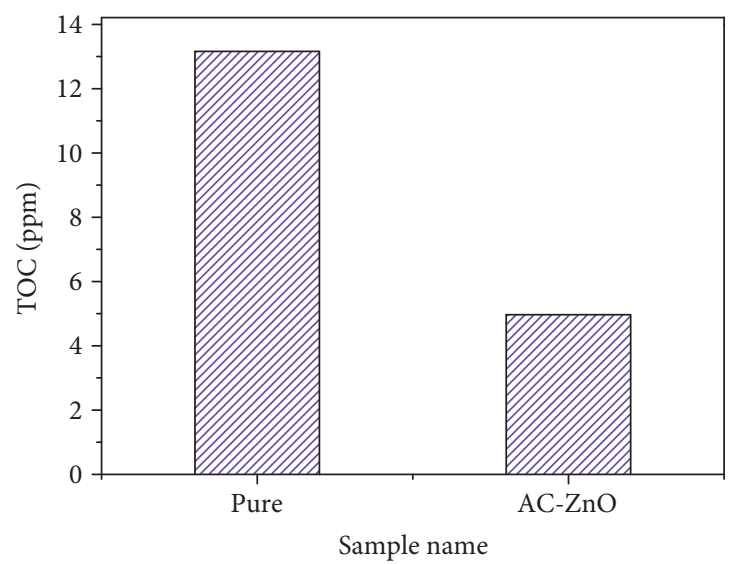

FIgURE 9: TOC of EV $\left(C_{0}=20 \mathrm{ppm}\right)$ before and after $120 \mathrm{~min}$. of degradation using AC-ZnO under UV-illumination.

the activated carbon. A closer observation indicates the flake-like $\mathrm{ZnO}$ structure on the surface of activated carbon.

3.8. Fourier Transform Infrared Spectroscopic Analysis (FT-IR). FT-IR studies of AC-ZnO (Figure S3) indicated that the band at around $3470 \mathrm{~cm}^{-1}$ is due to the $\mathrm{O}-\mathrm{H}$ stretching vibration mode of hydroxyl functional groups [39]. The stretching at a wave number of $2920 \mathrm{~cm}^{-1}$ is due to the $\mathrm{C}-\mathrm{H}$ stretching, while the band visible near $2360 \mathrm{~cm}^{-1}$ corresponds to the $\mathrm{C}-\mathrm{O}$ stretching vibration of the carbon monoxide or carbon dioxide derivatives. The stretching vibration band at around $1700 \mathrm{~cm}^{-1}$ is assigned to the carbonyl $\mathrm{C}=\mathrm{O}$ group, and the band at $1600 \mathrm{~cm}^{-1}$ is attributed to the $\mathrm{sp}^{2}$ character of $\mathrm{C}=\mathrm{C}$. The peak at around $1500 \mathrm{~cm}^{-1}$ is assigned to aromatic skeletal vibration. The bands between 900 and $1300 \mathrm{~cm}^{-1}$ can be attributed to the $\mathrm{C}-\mathrm{OH}$ groups. 


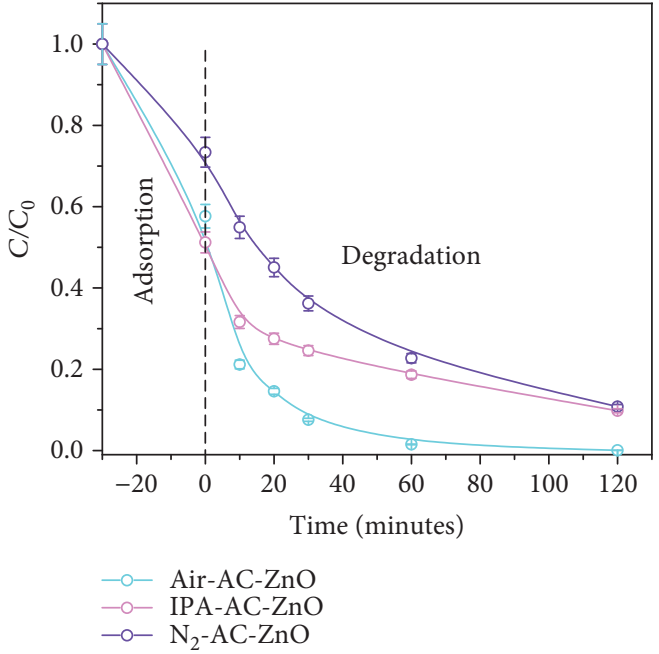

(a)

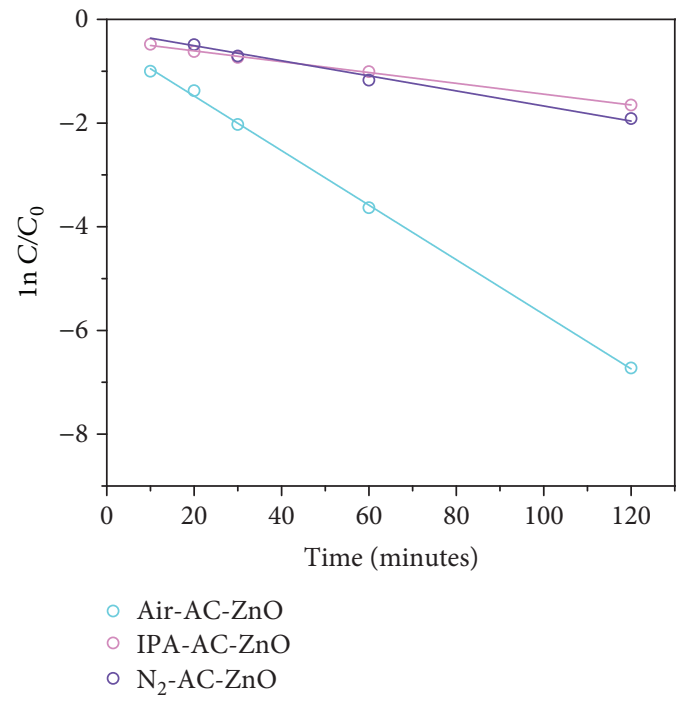

(b)

Figure 10: Plot of (a) $C / C_{0}$ vs. time under UV illumination with scavenging agents and (b) $\ln \left(C / C_{0}\right)$ vs. time.

The peaks appearing between 450 and $630 \mathrm{~cm}^{-1}$ are assigned to the $\mathrm{Zn}$-oxygen $(\mathrm{Zn}-\mathrm{O})$ stretching mode $[53,54]$.

3.9. Photocatalytic Degradation of Ethyl Violet (EV). The suspension made with $25 \mathrm{mg}$ of the catalyst, AC-ZnO, and $50 \mathrm{~mL}$ of $20 \mathrm{ppm}$ dye solution was first stirred for $30 \mathrm{~min}$. in the dark, to attain an adsorption-desorption equilibrium. It was found that the adsorption-desorption equilibrium is attained within $30 \mathrm{~min}$. The amount of Ethyl Violet adsorbed after $120 \mathrm{~min}$. was calculated to be $q_{\text {equilibrium }}=16.96 \mathrm{mg} / \mathrm{g}$. Then the reactor was illuminated. Similar experiments were done without the catalyst for comparison purposes. Only discolouration was observed with the dye solution when the photolysis was performed without the catalyst, whereas the degradation occurred (the degradation profile is illustrated in Figure S4) when the catalyst was used. Figure 8 illustrates the relative concentration $\left(C / C_{0}\right)$ of the remnant dye solution against irradiation time.

It can be seen that a reasonable adsorption was attained in the dark and the concentration reached zero (complete degradation) after $60 \mathrm{~min}$. of irradiation in the presence of a catalyst with the rate constant of $k_{\mathrm{AC}-\mathrm{ZnO}}=0.063 \mathrm{~min}^{-1}$. The solution without a catalyst reached an equilibrium after $120 \mathrm{~min}$. of irradiation, and the rate constant of the direct photolysis was found to $0.0058 \mathrm{~min}^{-1}$. These observations clearly indicate the effectiveness of the photocatalyst.

In a reported work, Chen studied the degradation of Ethyl Violet (EV) dye using a $\mathrm{ZnO}$ nanoparticle $(0.5 \mathrm{~g} / \mathrm{L})$ under UV illumination $(365 \mathrm{~nm})$. The initial concentration of the dye chosen for their study was $50 \mathrm{mg} / \mathrm{L}$, and it was found that $99.9 \%$ of EV was removed after $5 \mathrm{~h}$ irradiation [1]. In another study, Chen with his coworkers examined the degradation of $\mathrm{EV}$ dye using $\mathrm{TiO}_{2}$ suspension under visible light irradiation.

Photocatalytic degradation of EV dye mediated by $\mathrm{TiO}_{2}$ under anaerobic condition was reported by Lee and Chen,

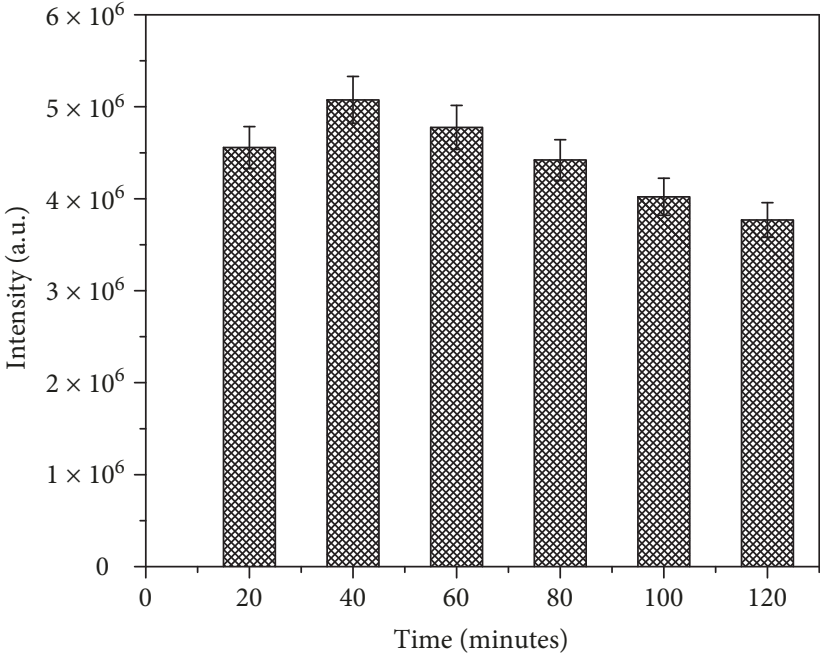

FIgURE 11: ${ }^{\circ} \mathrm{OH}$ trapping experiment over $\mathrm{AC}-\mathrm{ZnO}$ under UV illumination.

where they mainly focused on the degraded products and the cleavage mechanism.

In another study, Wang et al. used a $\mathrm{TiO}_{2}$ catalyst doped with an upconversion luminescence agent for the degradation of EV (initial concentration of $10 \mathrm{mg} / \mathrm{L}$ ), and they found that the degradation rate of Ethyl Violet in the presence of a doped rutile $\mathrm{TiO}_{2}$ photocatalyst reached $87.08 \%$ under $4 \mathrm{~h}$ of visible light irradiation, and it was observed that the rate of degradation was found to be higher than that of the undoped $\mathrm{TiO}_{2}$ material (35.42\%) [55]. In comparison to all these reported works, it can be clearly stated that our material is more effective, since it can completely degrade the dye in 60 min. of irradiation.

Band gap excitation of $\mathrm{AC}-\mathrm{ZnO}$ results in the promotion of electrons from the valence band to the conduction band edge. These electrons can readily react with oxygen molecules 


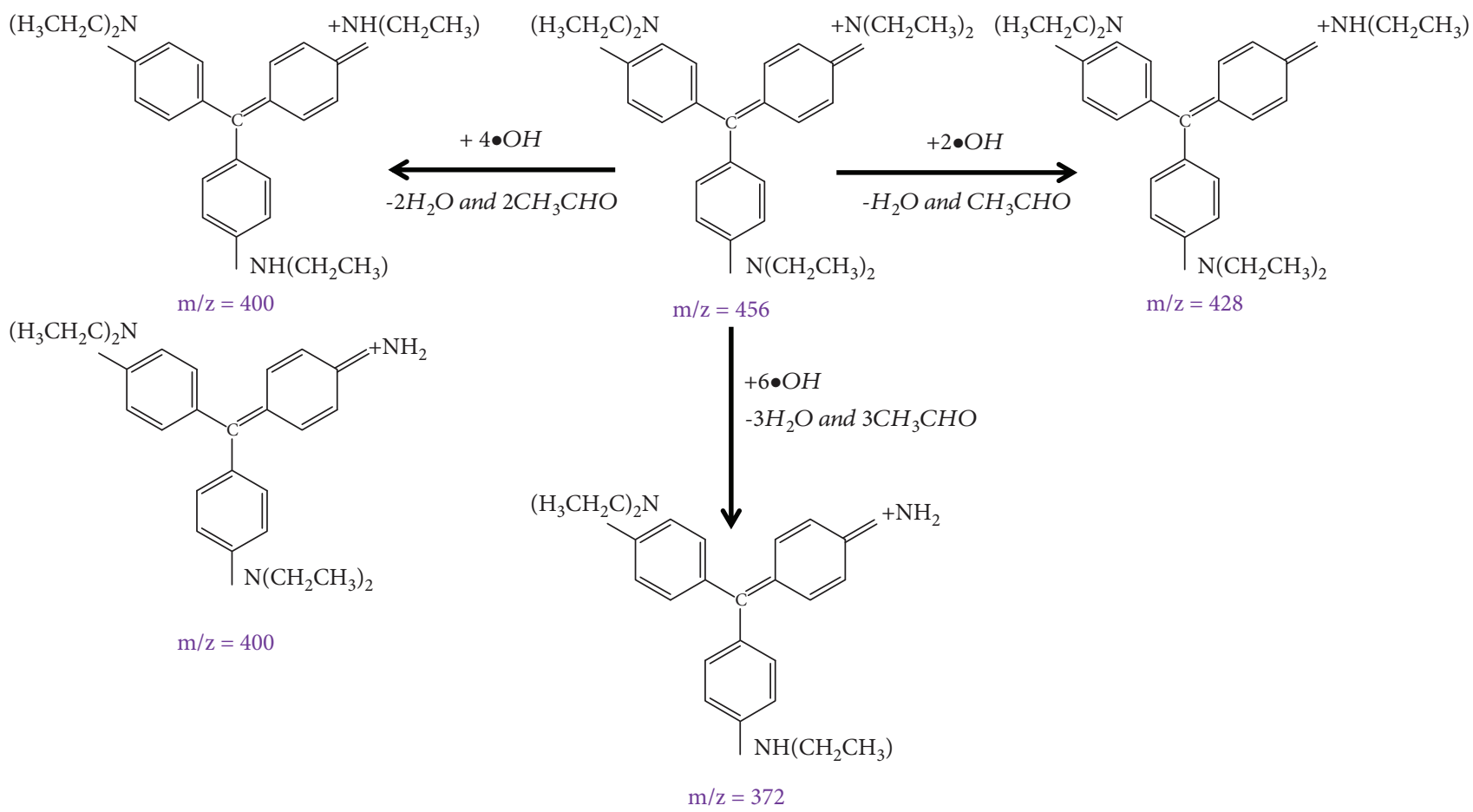

Scheme 1: The primary degraded products of EV dye.

to produce reactive oxygen species (ROS), such as $\mathrm{O}_{2}^{\bullet^{-}}$, $\bullet \mathrm{OOH}$, and ${ }^{\bullet} \mathrm{OH}$ [56]. These ROS then attack the dye molecule and destroy its auxochromic groups leading to destruction of the ring structure. Equation (1) describes the photocatalytic degradation process involving $\mathrm{EV}$.

$$
\begin{aligned}
&\left.\mathrm{AC}-\mathrm{ZnO} \stackrel{\mathrm{hv}}{\rightarrow} \mathrm{e}^{-} \text {(c.b.) }+\mathrm{h}^{+} \text {(v.b. }\right) \\
& \mathrm{e}^{-}+\mathrm{O}_{2} \rightarrow \mathrm{O}_{2}^{\bullet^{-}}, \\
& \mathrm{O}_{2}^{\bullet^{-}}+\mathrm{H}^{+} \rightarrow \cdot \mathrm{OOH}, \\
& \mathrm{OOH}^{\circ} \mathrm{O}_{2}^{\bullet^{-}}+\mathrm{H}^{+} \rightarrow \mathrm{O}_{2}+\mathrm{H}_{2} \mathrm{O}_{2}, \\
& \mathrm{O}_{2}^{\bullet^{-}}+\mathrm{H}_{2} \mathrm{O}_{2} \rightarrow{ }^{\bullet} \mathrm{OH}+\mathrm{OH}^{-}+\mathrm{O}_{2}, \\
& \mathrm{EV}+\mathrm{ROS} \rightarrow \text { photo-degraded products }
\end{aligned}
$$

Although discolouration was observed during the photocatalysis process, it is not an indication of the complete removal of the dye from the aqueous solution. However, a shift in the prominent absorption band at $\lambda_{\max }$ of $596 \mathrm{~nm}$ indicates the cleavage of the auxochromic group of the EV dye molecule $[57,58]$. The decrease in the organic contents during the degradation process was further confirmed by TOC studies. Figure 9 represents the total organic contents after photocatalytic degradation of EV in comparison to the TOC of original dye solution used in this study. It can be seen that the total organic carbon content present in the EV solution decreases during the degradation and a $63 \%$ decrease in concentration of EV dye was attained after 120 min. of degradation. These results indicate that although the remnant solution became colourless after degradation, there are some organic residues existing in the resultant solution, which may be the by-products formed during degradation.

3.10. Photocatalysis in the Presence of Scavenging Agents. In order to understand the role of ROS and identify the most prominent ROS species, photocatalytic experiments were carried out in the presence of scavenging agents. The impact of the different scavenging agents on the dye removal efficiencies was investigated with the catalyst prepared. To investigate the role of oxygen $\left(\mathrm{O}_{2}\right), \mathrm{N}_{2}$ flow was used to degasify the suspension throughout the study and isopropyl alcohol (IPA) was used as the ${ }^{\bullet} \mathrm{OH}$ trapping agent in the degradation process of EV dye to provide more insight about the role of $\mathrm{OH}$ radical. The obtained results for the two scavenging agents are represented in Figure 10(a), and the values obtained for the apparent rate constant, $k_{\text {app }}\left(\mathrm{min}^{-1}\right)$, are 0.014 and 0.010 .

From the results, we can conclude that the rate of the reaction is very low, when these scavenging agents are used. Thus, the presence of dissolved oxygen plays an important role in degrading the dye molecules by providing the reactive oxygen species, such as superoxide radicals and hydroxyl radicals. Also, the results showed that the degradations obey pseudo-first-order kinetics with the $R^{2}$ values of 0.986 (under $\mathrm{N}_{2}$ flow) and 0.997 (with IPA) and the apparent rate constant $\left(k_{\text {app }}\right)$ was calculated from the plot of $\ln \left(C / C_{0}\right)$ vs. time (Figure 10(b)).

3.11. Photoluminescence (PL) Spectroscopic Studies. It is known that hydroxyl radicals play an important role in the degradation of organic pollutants. To shed more light on this, - $\mathrm{OH}$ trapping experiments were carried out. These radicals can react with terephthalic acid (TPA) and form fluorescent 


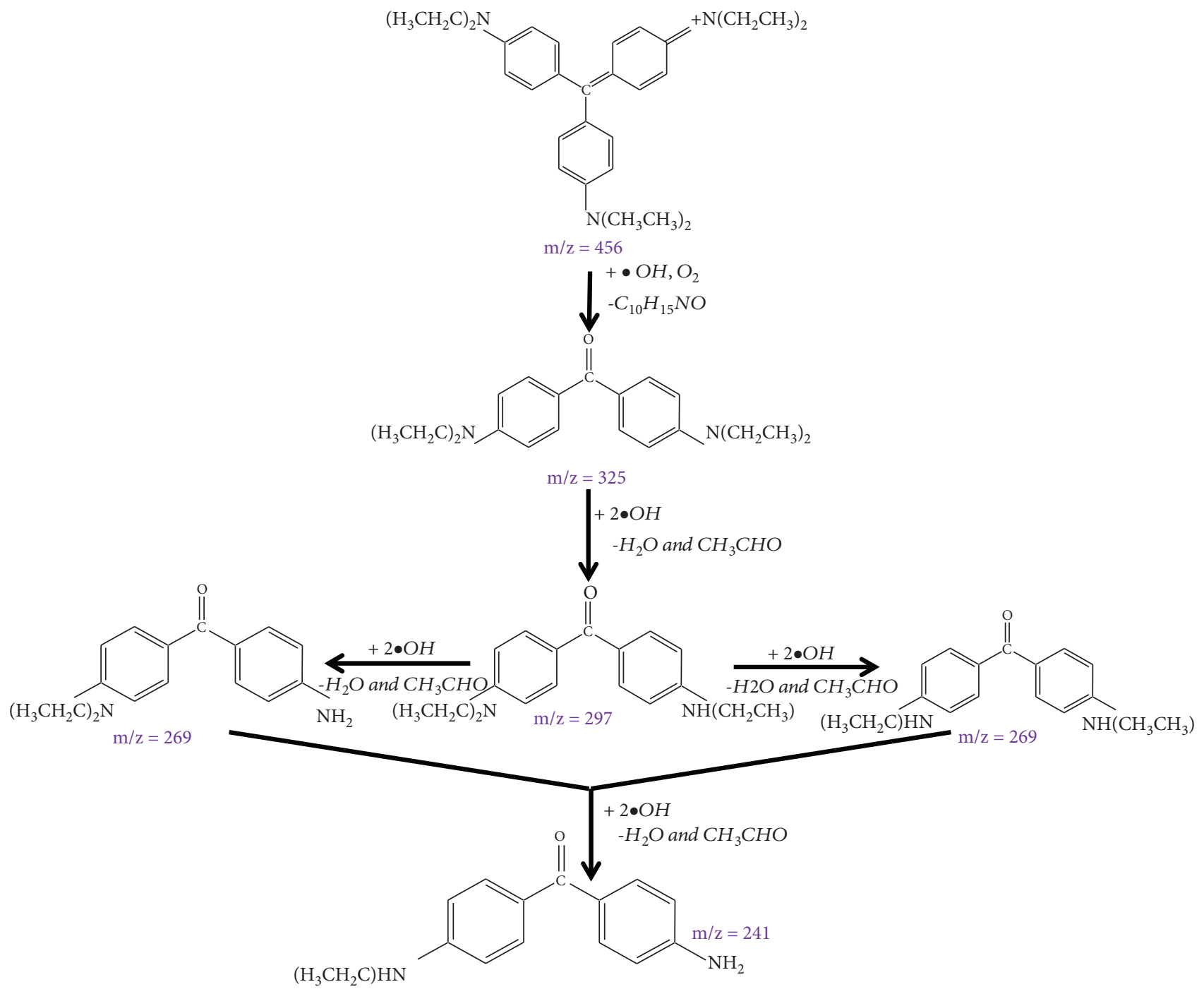

Scheme 2: The secondary degraded products of EV dye.

2-hydroxyterephthalic acid (2-HTPA), and the formation of 2-HTPA is proportional to the amount of ${ }^{\bullet} \mathrm{OH}$ formed. Figure 11 illustrates a plot of fluorescence intensity for 2-HTPA at different times for the catalyst used in this study.

It can be seen from Figure 11 that the maximum photoluminescence (PL) intensity of $5 \times 10^{6}$ (a.u.) was recorded after $40 \mathrm{~min}$. of irradiation. This means that the generation of the ${ }^{\bullet} \mathrm{OH}$ radicals by this system reaches its maximum at $40 \mathrm{~min}$., and then the rate of formation started to decrease. This phenomenon is reflected in the rate of degradation of $\mathrm{EV}$, where a fast degradation is attained until $40 \mathrm{~min}$. of time and the rate of degradation is found to be slow after $40 \mathrm{~min}$. (Figure 10(a)) of the degradation time. It is noteworthy to mention that 2-HTPA which is formed during the process can be further degraded by $\bullet \mathrm{OH}$. Since the trapping agent can itself be degraded, the formation of $\bullet \mathrm{OH}$ radical seems to decrease after $40 \mathrm{~min}$.

3.12. ESI-MS Analysis. The intermediates formed during the degradation of EV dye was evaluated from the ESI-MS analysis, and the structures of molecular fragments detected by mass spectrometry are summarized in Schemes 1-3. The mass spectrum of pure EV dye solution shows two major peaks at $m / z=456$ and 428 under our experimental conditions. The disappearance of the parent peak $(m / z=456)$ was achieved after $120 \mathrm{~min}$. of degradation. In addition, a decrease in the intensity (counts) of this major peak with time and formation of several other peaks at lower $m / z$ values further validate the degradation of the EV dye molecule in the presence of the catalyst, AC- $\mathrm{ZnO}$, (Figure S5). On the basis of these results, a general mechanism of photocatalytic degradation of EV dye is proposed. The mechanism consists of several steps that include (i) N-de-ethylation, (ii) destruction of the conjugated structure, and (iii) oxidative degradation. The primary cleavage of the EV dye results in the formation of peaks with $m / z=428,400$, and 372, which are mainly due to the addition of ${ }^{\bullet} \mathrm{OH}$ radical and the subsequent removal of water and acetaldehyde molecules, respectively, as indicated in Scheme 1.

The cleavage of the ring structure from the original molecule $(m / z=456)$ leads to the secondary degraded products with the $m / z$ values of $325,297,269$, and 241 . This may be 


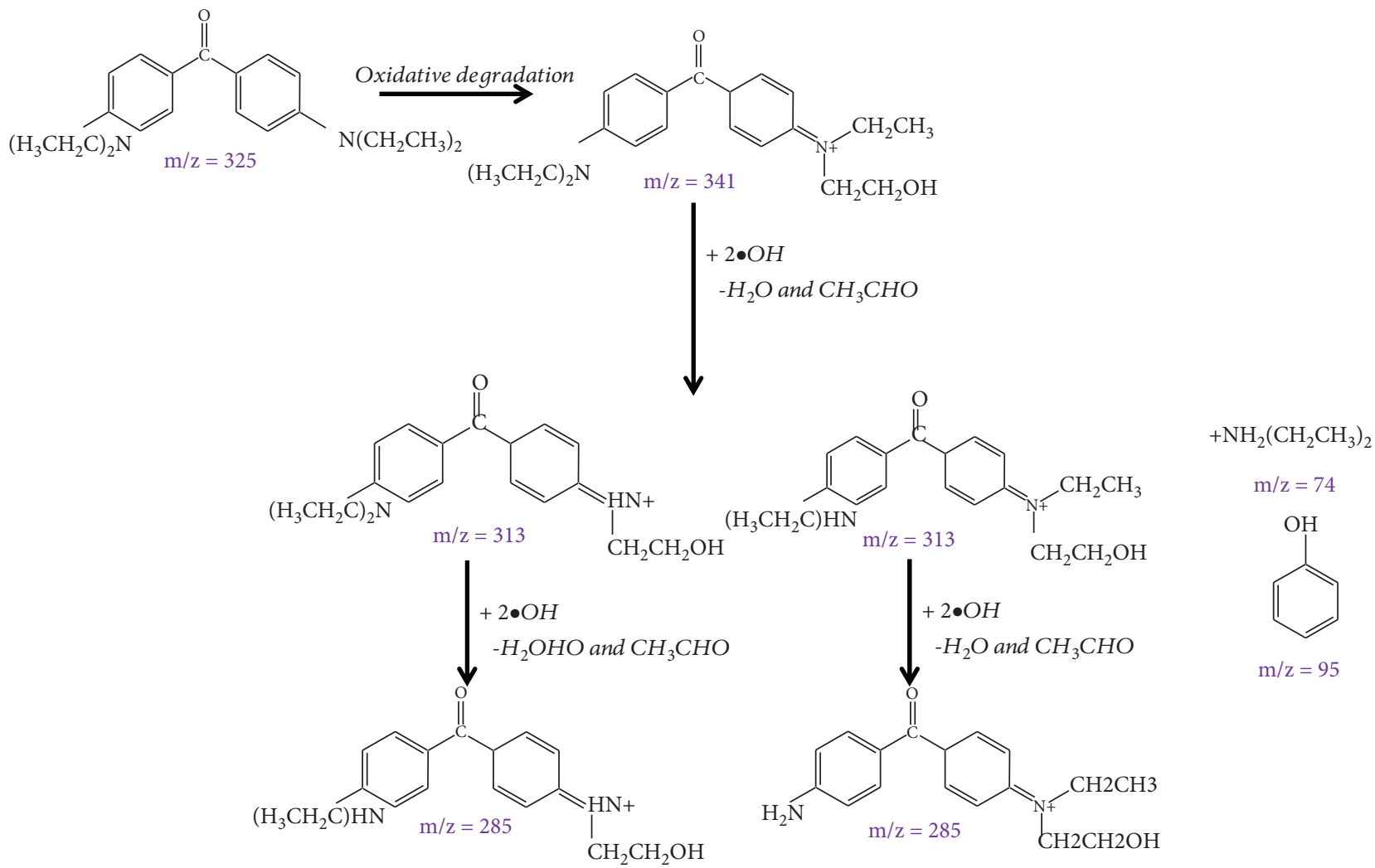

Scheme 3: The tertiary degraded products of EV dye.

due to the addition of ${ }^{\bullet} \mathrm{OH}$ radicals and the removal of water and acetaldehyde molecules as illustrated in Scheme 2. Further cleavage of these degraded molecules results in the formation of secondary products with $\mathrm{m} / z$ values of 341, 313, and 285. The small fragmented products, i.e., tertiary products, detected in this study at $\mathrm{m} / z$ values of 95 and 74 are phenol and diethylamine, respectively, as illustrated in Scheme 3.

\section{Conclusions}

A sustainable and versatile photocatalyst, AC- $\mathrm{ZnO}$, was prepared by a facile method using Algerian olive-waste cakes as raw material for activated carbon. Impregnation method was utilized to load $\mathrm{ZnO}$ on the activated carbon support. Degradation of the Ethyl Violet (EV) dye was evaluated with the prepared catalyst $\mathrm{AC}-\mathrm{ZnO}$, and the kinetic study suggests that the rate of the degradation obeys pseudo-first-order kinetics. The intermediate products formed during the photocatalytic degradation of EV were identified by using ESI-MS analysis, and a degradation mechanism was proposed. The total organic contents (TOC) were found to decrease after $120 \mathrm{~min}$. of degradation. Further, the scavenging experiments indicate that dissolved oxygen is important to achieve faster and effective degradation, since this dissolved oxygen leads to the formation of reactive oxygen species, such as superoxide and hydroxyl radicals. Overall, this study exemplifies the usage of the Algerian olive waste for the preparation of activated carbon and, thus, provides opportunity to reduce these wastes, as well as reduce the cost for importing activated carbon to countries like Algeria. Further, modifying this activated carbon material using active oxide materials, such as $\mathrm{TiO}_{2}$ and $\mathrm{ZnO}$, will open up the opportunity to introduce cheaper catalysts to the market for environmental remediation applications.

\section{Data Availability}

The data sets obtained during the research and the analysis are already available in the article and the supplementary document. However, if there are any information/data that are needed, these may be obtained from the corresponding author on a reasonable request.

\section{Conflicts of Interest}

The authors declare that there is no conflict of interest regarding the publication of this paper.

\section{Acknowledgments}

Authors would like to acknowledge the National Science Foundation (CHE-1337707) for the financial support in purchasing the SEM instrument and Dr. Aravind Baride, who assisted with the SEM analysis. 


\section{Supplementary Materials}

Supplementary 1. Scheme S1: different steps involved in the preparation of the catalyst, AC-ZnO. Table S1: optimal instrumental conditions for ESI-MS studies. Figure S1: powder X-ray diffraction patterns of blank activated carbon (AC). Figure S2: TGA of blank activated carbon (AC). Figure S3: FT-IR spectrum of AC-ZnO. Figure S4: absorption spectra of EV dye (after filtration) at various time intervals during UV light irradiation for $120 \mathrm{~min}$. using AC-ZnO. Figure S5: mass spectrum (MS) of the by-products generated during the degradation of Ethyl Violet by the system (AC- $\mathrm{ZnO} / \mathrm{UV}$ ) at different times.

Supplementary 2. Graphical Abstract: the first two pictures of the graphical abstract explain how the oil waste was collected from the site and the activated charcoal preparation process. Then the scheme illustrates the ZnO-loaded activated carbon; the next photograph taken during the degradation process indicates the irradiation source and the photoreactor setup. The final photograph illustrates the dye solution withdrawn in different time intervals. Disappearance of the colour indicates the degradation of the dye material.

\section{References}

[1] C.-C. Chen, "Degradation pathways of ethyl violet by photocatalytic reaction with $\mathrm{ZnO}$ dispersions," Journal of Molecular Catalysis A: Chemical, vol. 264, no. 1-2, pp. 82-92, 2007.

[2] S. Chakrabarti and B. Dutta, "Photocatalytic degradation of model textile dyes in wastewater using $\mathrm{ZnO}$ as semiconductor catalyst," Journal of Hazardous Materials, vol. 112, no. 3, pp. 269-278, 2004.

[3] G. Kumar, R. Kumar, S. W. Hwang, and A. Umar, "Photocatalytic degradation of direct red-23 dye with $\mathrm{ZnO}$ nanoparticles," Journal of Nanoscience and Nanotechnology, vol. 14, no. 9, pp. 7161-7166, 2014.

[4] S. Khezrianjoo and H. D. Revanasiddappa, "Photocatalytic degradation of acid yellow 36 using zinc oxide photocatalyst in aqueous media," Journal of Catalysts, vol. 2013, Article ID 582058, 6 pages, 2013.

[5] J. Kaur, S. Bansal, and S. Singhal, "Photocatalytic degradation of methyl orange using $\mathrm{ZnO}$ nanopowders synthesized via thermal decomposition of oxalate precursor method," Physica B: Condensed Matter, vol. 416, no. 1, pp. 33-38, 2013.

[6] S. Rasalingam, C. M. Wu, and R. T. Koodali, "Modulation of pore sizes of titanium dioxide photocatalysts by a facile template free hydrothermal synthesis method: implications for photocatalytic degradation of rhodamine B," ACS Applied Materials \& Interfaces, vol. 7, no. 7, pp. 43684380, 2015.

[7] R. Ullah and J. Dutta, "Photocatalytic degradation of organic dyes with manganese-doped $\mathrm{ZnO}$ nanoparticles," Journal of Hazardous Materials, vol. 156, no. 1-3, pp. 194-200, 2008.

[8] M. Vinayagam, S. Ramachandran, V. Ramya, and A. Sivasamy, "Photocatalytic degradation of orange $\mathrm{G}$ dye using $\mathrm{ZnO} /$ biomass activated carbon nanocomposite," Journal of Environmental Chemical Engineering, vol. 6, no. 3, pp. 3726-3734, 2018.

[9] X. Bai, C. Sun, D. Liu et al., "Photocatalytic degradation of deoxynivalenol using graphene/ $\mathrm{ZnO}$ hybrids in aqueous suspension," Applied Catalysis B: Environmental, vol. 204, no. 1, pp. 11-20, 2017.

[10] K. Byrappa, A. K. Subramani, S. Ananda et al., "Impregnation of $\mathrm{ZnO}$ onto activated carbon under hydrothermal conditions and its photocatalytic properties," Journal of Materials Science, vol. 41, no. 5, pp. 1355-1362, 2006.

[11] T. Tsumura, N. Kojitani, H. Umemura, M. Toyoda, and M. Inagaki, "Composites between photoactive anatase-type $\mathrm{TiO}_{2}$ and adsorptive carbon," Applied Surface Science, vol. 196, no. 1-4, pp. 429-436, 2002.

[12] R. Baccar, J. Bouzid, M. Feki, and A. Montiel, "Preparation of activated carbon from Tunisian olive-waste cakes and its application for adsorption of heavy metal ions," Journal of Hazardous Materials, vol. 162, no. 2-3, pp. 1522-1529, 2009.

[13] K. Okada, N. Yamamoto, Y. Kameshima, and A. Yasumori, "Porous properties of activated carbons from waste newspaper prepared by chemical and physical activation," Journal of Colloid and Interface Science, vol. 262, no. 1, pp. 179193, 2003.

[14] G. San Miguel, G. D. Fowler, and C. J. Sollars, "A study of the characteristics of activated carbons produced by steam and carbon dioxide activation of waste tyre rubber," Carbon, vol. 41, no. 5, pp. 1009-1016, 2003.

[15] Y. Guo and D. A. Rockstraw, "Activated carbons prepared from rice hull by one-step phosphoric acid activation," Microporous and Mesoporous Materials, vol. 100, no. 1-3, pp. 12-19, 2007.

[16] R. L. Tseng, S. K. Tseng, and F. C. Wu, "Preparation of high surface area carbons from corncob with $\mathrm{KOH}$ etching plus $\mathrm{CO}_{2}$ gasification for the adsorption of dyes and phenols from water," Colloids and Surfaces A: Physicochemical and Engineering Aspects, vol. 279, no. 1-3, pp. 69-78, 2006.

[17] B. Karagozoglu, M. Tasdemir, E. Demirbas, and M. Kobya, "The adsorption of basic dye (Astrazon Blue FGRL) from aqueous solutions onto sepiolite, fly ash and apricot shell activated carbon: kinetic and equilibrium studies," Journal of Hazardous Materials, vol. 147, no. 1-2, pp. 297-306, 2007.

[18] C. Bouchelta, M. S. Medjram, O. Bertrand, and J. P. Bellat, "Preparation and characterization of activated carbon from date stones by physical activation with steam," Journal of Analytical and Applied Pyrolysis, vol. 82, no. 1, pp. 70-77, 2008.

[19] I. A. W. Tan, A. L. Ahmad, and B. H. Hameed, "Adsorption of basic dye on high-surface-area activated carbon prepared from coconut husk: equilibrium, kinetic and thermodynamic studies," Journal of Hazardous Materials, vol. 154, no. 1-3, pp. 337-346, 2008.

[20] G. Cimino, R. M. Cappello, C. Caristi, and G. Toscano, "Characterization of carbons from olive cake by sorption of wastewater pollutants," Chemosphere, vol. 61, no. 7, pp. 947-955, 2005.

[21] A. Baçaoui, A. Yaacoubi, A. Dahbi et al., "Optimization of conditions for the preparation of activated carbons from olive-waste cakes," Carbon, vol. 39, no. 3, pp. 425-432, 2001.

[22] L. Louadj and A. Giuffré, "Analytical characteristics of olive oil produced with three different processes in Algeria," La Rivista Italiana Delle Sostanze Grasse, vol. 87, no. 3, pp. 186-195, 2010.

[23] C. Moreno-Castilla, F. Carrasco-Marín, M. V. López-Ramón, and M. A. Alvarez-Merino, "Chemical and physical activation of olive-mill waste water to produce activated carbons," Carbon, vol. 39, no. 9, pp. 1415-1420, 2001. 
[24] F. Sellami, R. Jarboui, S. Hachicha, K. Medhioub, and E. Ammar, "Co-composting of oil exhausted olive-cake, poultry manure and industrial residues of agro-food activity for soil amendment," Bioresource Technology, vol. 99, no. 5, pp. 11771188, 2008.

[25] R. Selvasembian and B. P, "Utilization of unconventional lignocellulosic waste biomass for the biosorption of toxic triphenylmethane dye malachite green from aqueous solution," International Journal of Phytoremediation, vol. 20, no. 6, pp. 624-633, 2018.

[26] W. Azmi, R. K. Sani, and U. C. Banerjee, "Biodegradation of triphenylmethane dyes," Enzyme and Microbial Technology, vol. 22, no. 3, pp. 185-191, 1998.

[27] R. Ahmad and P. K. Mondal, "Application of acid treated almond peel for removal and recovery of brilliant green from industrial wastewater by column operation," Separation Science and Technology, vol. 44, no. 7, pp. 1638-1655, 2009.

[28] U. Shedbalkar, R. Dhanve, and J. Jadhav, "Biodegradation of triphenylmethane dye cotton blue by Penicillium ochrochloron MTCC 517," Journal of Hazardous Materials, vol. 157, no. 2-3, pp. 472-479, 2008.

[29] A. Jasińska, S. Różalska, P. Bernat, K. Paraszkiewicz, and J. Długoński, "Malachite green decolorization by nonbasidiomycete filamentous fungi of Penicillium pinophilum and Myrothecium roridum," International Biodeterioration \& Biodegradation, vol. 73, pp. 33-40, 2012.

[30] W. Au, S. Pathak, C. J. Collie, and T. C. Hsu, "Cytogenetic toxicity of gentian violet and crystal violet on mammalian cells in vitro," Mutation Research/Genetic Toxicology, vol. 58, no. 2-3, pp. 269-276, 1978.

[31] S. H. Lee and C. S. Choi, "Chemical activation of high sulfur petroleum cokes by alkali metal compounds," Fuel Processing Technology, vol. 64, no. 1-3, pp. 141-153, 2000.

[32] A. Ahmadpour and D. D. Do, "The preparation of active carbons from coal by chemical and physical activation," Carbon, vol. 34, no. 4, pp. 471-479, 1996.

[33] P. Ehrburger, A. Addoun, F. Addoun, and J. B. Donnet, "Carbonization of coals in the presence of alkaline hydroxides and carbonates: formation of activated carbons," Fuel, vol. 65, no. 10, pp. 1447-1449, 1986.

[34] N. Rie, N. Yoko, O. Naoto, and I. Michio, "Modification of pore structure in activated carbons by heat treatment with thermoplastic resins," New Carbon Materials, vol. 21, no. 4, pp. 289-296, 2006.

[35] Z. Hu, H. Guo, M. P. Srinivasan, and N. Yaming, "A simple method for developing mesoporosity in activated carbon," Separation and Purification Technology, vol. 31, no. 1, pp. 47-52, 2003.

[36] A. N. Wennerberg and T. M. O'GradyUS Patent 4,082,694.

[37] H. Marsh, D. S. Yan, T. M. O'Grady, and A. Wennerberg, "Formation of active carbons from cokes using potassium hydroxide," Carbon, vol. 22, no. 6, pp. 603-611, 1984.

[38] G. G. Stavropoulos and A. A. Zabaniotou, "Production and characterization of activated carbons from olive-seed waste residue," Microporous and Mesoporous Materials, vol. 82, no. 1-2, pp. 79-85, 2005

[39] H. P. S. A. Khalil, M. Jawaid, P. Firoozian, U. Rashid, A. Islam, and H. M. Akil, "Activated carbon from various agricultural wastes by chemical activation with $\mathrm{KOH}$ : preparation and characterization," Journal of Biobased Materials and Bioenergy, vol. 7, no. 6, pp. 708-714, 2013.
[40] J. Jayachandiran, A. Raja, M. Arivanandhan, R. Jayavel, and D. Nedumaran, "A facile synthesis of hybrid nanocomposites of reduced graphene oxide/ $\mathrm{ZnO}$ and its surface modification characteristics for ozone sensing," Journal of Materials Science: Materials in Electronics, vol. 29, no. 4, pp. 3074-3086, 2018.

[41] D. M. Cunha, N. M. Ito, A. M. Xavier, J. T. Arantes, and F. L. Souza, "Zinc oxide flower-like synthesized under hydrothermal conditions," Thin Solid Films, vol. 537, no. 1, pp. 97101, 2013.

[42] N. Bel Hadj Tahar, R. Bel Hadj Tahar, A. Ben Salah, and A. Savall, "Effects of individual layer thickness on the microstructure and optoelectronic properties of sol-gel-derived zinc oxide thin films," Journal of the American Ceramic Society, vol. 91, no. 3, pp. 846-851, 2008.

[43] R. E. Marotti, P. Giorgi, G. Machado, and E. A. Dalchiele, "Crystallite size dependence of band gap energy for electrodeposited $\mathrm{ZnO}$ grown at different temperatures," Solar Energy Materials \& Solar Cells, vol. 90, no. 15, pp. 2356-2361, 2006.

[44] P. Bindu and S. Thomas, "Estimation of lattice strain in $\mathrm{ZnO}$ nanoparticles: X-ray peak profile analysis," Journal of Theoretical and Applied Physics, vol. 8, no. 4, pp. 123-134, 2014.

[45] Y. H. Yang, B. Wang, and G. W. Yang, "Mechanisms of selfcatalyst growth of agave-like zinc oxide nanostructures on amorphous carbons," Crystal Growth \& Design, vol. 7, no. 7, pp. 1242-1245, 2007.

[46] W. Han, L. Ren, X. Qi et al., "Synthesis of CdS/ZnO/graphene composite with high-efficiency photoelectrochemical activities under solar radiation," Applied Surface Science, vol. 299, pp. 12-18, 2014.

[47] X. Wang, X. Liang, Y. Wang et al., "Adsorption of copper (II) onto activated carbons from sewage sludge by microwave induced phosphoric acid and zinc chloride activation," Desalination, vol. 278, no. 1-3, pp. 231-237, 2011.

[48] D. P. Joseph and C. Venkateswaran, "Bandgap engineering in $\mathrm{ZnO}$ by doping with $3 \mathrm{~d}$ transition metal ions," Journal of Atomic, Molecular, and Optical Physics, vol. 2011, article 270540, 7 pages, 2011.

[49] D. Raoufi and T. Raoufi, "The effect of heat treatment on the physical properties of sol-gel derived $\mathrm{ZnO}$ thin films," Applied Surface Science, vol. 255, no. 11, pp. 5812-5817, 2009.

[50] H. Hartnagel, A. L. Dawar, A. K. Jain, and C. Jagadish, Semiconducting Transparent Thin Films, Institute of Physics Publishing, 1995.

[51] J. I. Pankove, Optical Progress in Semiconductors, Dover publication, New York, 1975.

[52] S. Rasalingam, H. S. Kibombo, C. M. Wu, R. Peng, J. Baltrusaitis, and R. T. Koodali, "Competitive role of structural properties of titania-silica mixed oxides and a mechanistic study of the photocatalytic degradation of phenol," Applied Catalysis B: Environmental, vol. 148-149, pp. 394405, 2014.

[53] Y. Li and X. Liu, "Activated carbon/ZnO composites prepared using hydrochars as intermediate and their electrochemical performance in supercapacitor," Materials Chemistry and Physics, vol. 148, no. 1-2, pp. 380-386, 2014.

[54] M. Ghaedi, A. Ansari, M. H. Habibi, and A. R. Asghari, "Removal of malachite green from aqueous solution by zinc oxide nanoparticle loaded on activated carbon: kinetics and isotherm study," Journal of Industrial and Engineering Chemistry, vol. 20, no. 1, pp. 17-28, 2014. 
[55] J. Wang, G. Zhang, Z. Zhang et al., "Investigation on photocatalytic degradation of ethyl violet dyestuff using visible light in the presence of ordinary rutile $\mathrm{TiO}_{2}$ catalyst doped with upconversion luminescence agent," Water Research, vol. 40, no. 11, pp. 2143-2150, 2006.

[56] T. Wu, G. Liu, J. Zhao, H. Hidaka, and N. Serpone, "Photoassisted degradation of dye pollutants. V. Self-photosensitized oxidative transformation of rhodamine $B$ under visible light irradiation in aqueous $\mathrm{TiO}_{2}$ dispersions," The Journal of Physical Chemistry B, vol. 102, no. 30, pp. 5845-5851, 1998.

[57] C. C. Chen, C. S. Lu, and Y. C. Chung, "Photocatalytic degradation of ethyl violet in aqueous solution mediated by $\mathrm{TiO}_{2}$ suspensions," Journal of Photochemistry and Photobiology A: Chemistry, vol. 181, no. 1, pp. 120-125, 2006.

[58] F. D. Mai, W. L. W. Lee, J. L. Chang, S. C. Liu, C. W. Wu, and C. C. Chen, "Fabrication of porous $\mathrm{TiO}_{2}$ film on Ti foil by hydrothermal process and Its photocatalytic efficiency and mechanisms with ethyl violet dye," Journal of Hazardous Materials, vol. 177, no. 1-3, pp. 864-875, 2010. 

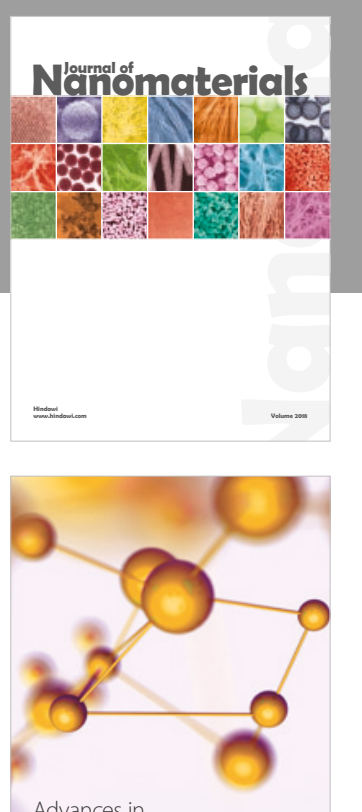

Physical Chemistry
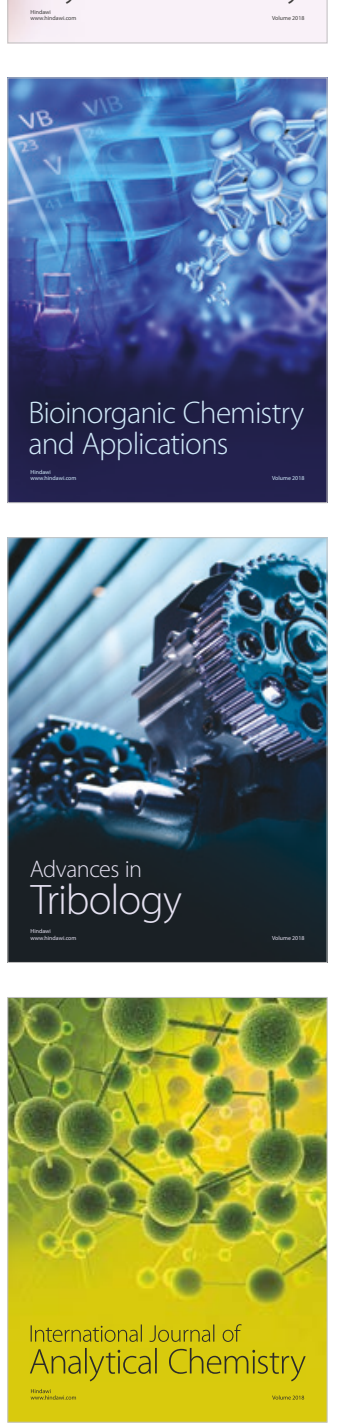

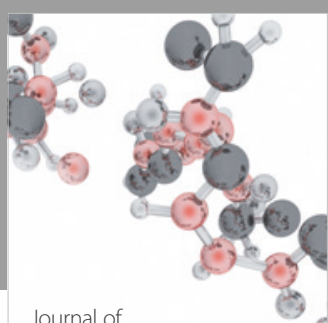

Analytical Methods

in Chemistry

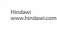

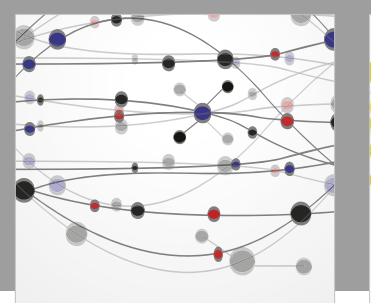

The Scientific World Journal

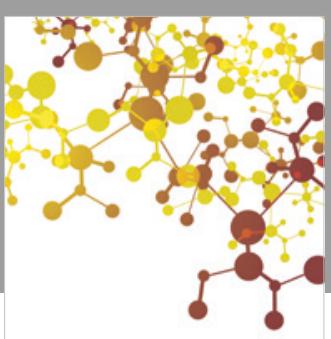

Journal of

Applied Chemistry
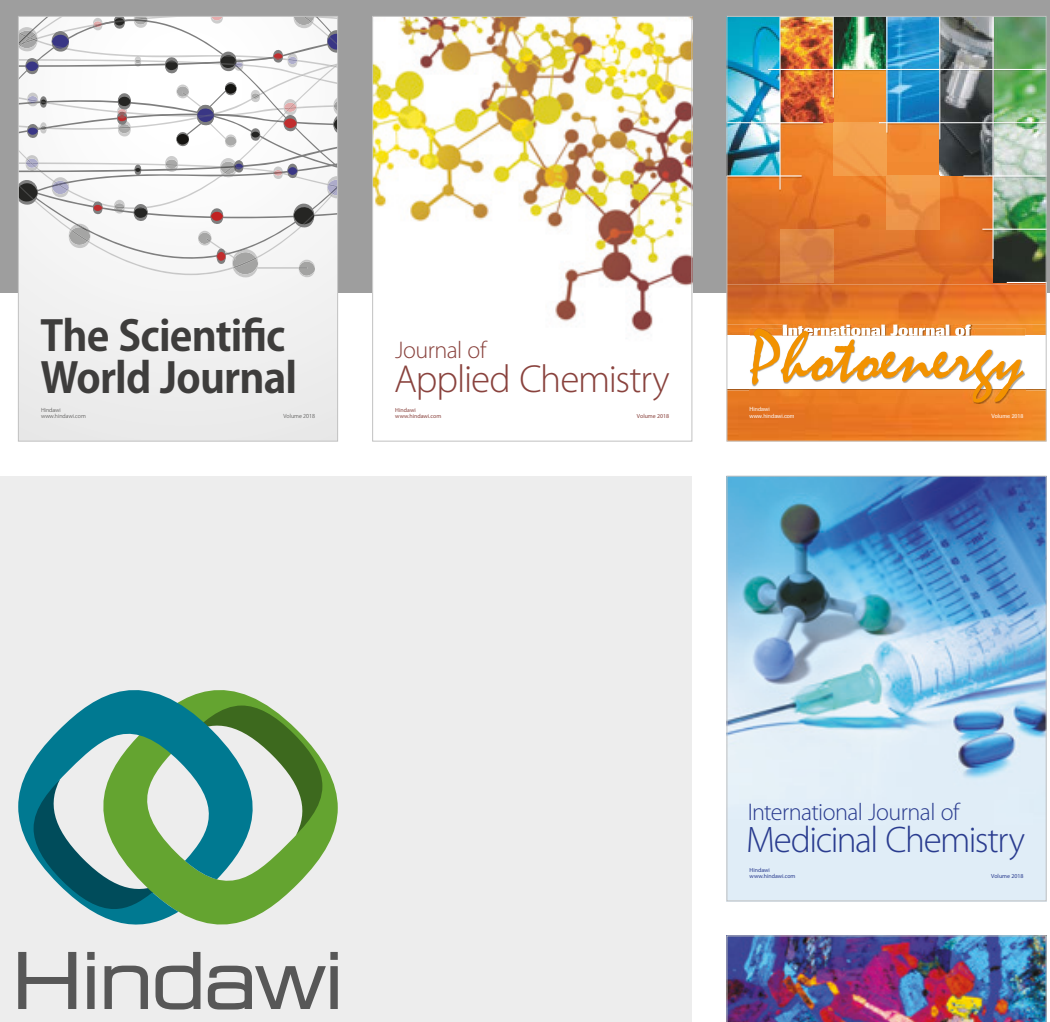

Submit your manuscripts at

www.hindawi.com
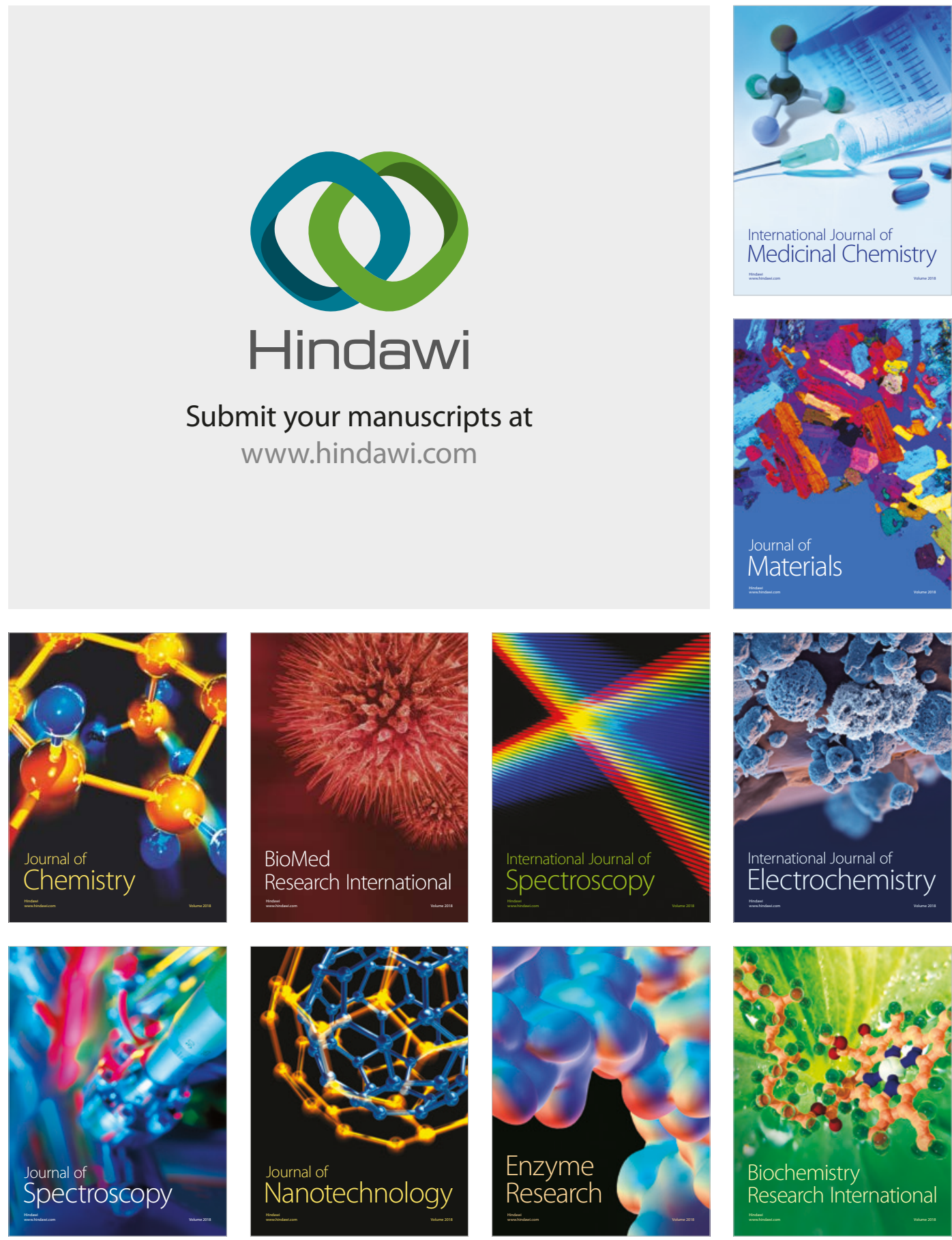
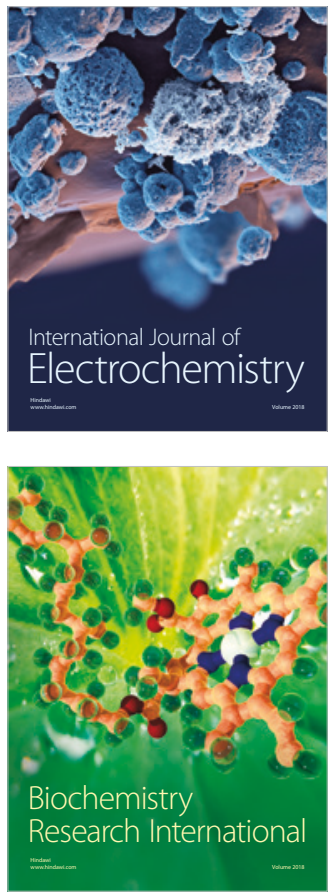